\title{
Health Canada's new guidelines for body weight classification in adults: challenges and concerns
}

\author{
Simone Lemieux, Lyne Mongeau, Marie-Claude Paquette, Suzanne Laberge, Brigitte Lachance; \\ for the members of the GTPPP (Québec Provincial Working Group on Weight Related Issues)
}

$\mathrm{I}$ n 2003 Health Canada released its new Canadian Guidelines for Body Weight Classification in Adults, ${ }^{1}$ an update of the weight classification system that had been in use in this country since $1988 .^{2}$ The guidelines were updated in response to advances in the understanding of the relation between body weight and health, and to address the appropriateness of the international adoption of the World Health Organization's weight classification released in 2000. ${ }^{3}$ The Québec Provincial Working Group on Weight Related Issues (GTPPP) has reviewed and analyzed the new guidelines. In this article we discuss the major changes in the guidelines, which are summarized in Table 1.

\section{The new definition of underweight}

Because the relation between body mass index (BMI) and mortality follows a J-shape curve $\mathrm{e}^{4,5}$ and health risks are significantly increased below a certain value of BMI, weight guidelines need to set a low boundary for normal weight. In the technical report of the 2003 guidelines, it is acknowledged that the evidence to support a low BMI cut-off point is weaker than for the other BMI cut-off points. In fact, most of the evidence comes from studies conducted in nonoccidental countries in which the association between low BMI and mortality was assessed using variable cut-off points (from 18.5 to $22.0 \mathrm{~kg} / \mathrm{m}^{2}$ ). Results from a Canadian study showing a J-curve relation between BMI and mortality, with increased risk below a BMI of $18.5 \mathrm{~kg} / \mathrm{m}^{2}$, was considered in the decision to lower the cut-off point from 20.0 to $18.5 \mathrm{~kg} / \mathrm{m}^{2}$.

Our group has some concerns about this new cut-off point. We recognize that some people with a BMI between 18.5 and $20.0 \mathrm{~kg} / \mathrm{m}^{2}$ are naturally thin and would be falsely identified as being at risk had the cut-off point been kept at $20 \mathrm{~kg} / \mathrm{m}^{2}$. However, in other people, especially older adults, a BMI between 18.5 and $20.0 \mathrm{~kg} / \mathrm{m}^{2}$ can be a marker of malnutrition, which needs to be identified. Lowering the BMI cut-off point could also delay the identification of eating disorders, for example among young girls. ${ }^{7}$ Although $\mathrm{BMI}$ is not the only criterion used to identify people with eating disorders, in the context of a periodical physical exam BMI measurement can be a first-line indicator of the need for further investigation. We fear that a lower BMI limit of $18.5 \mathrm{~kg} / \mathrm{m}^{2}$ lacks the sensitivity to identify underweight people with eating disorders who are falsely classified as normal. Granted, had the lower limit of $20 \mathrm{~kg} / \mathrm{m}^{2}$ been kept, perfectly healthy individuals could have been falsely identified as being underweight; however, this underweight label would probably not stigmatize these people, given that current social norms promote thinness.

\section{The new definition of overweight}

Overweight, defined as a BMI between 25 and $30 \mathrm{~kg} / \mathrm{m}^{2}$, is associated with increased health risks in the 2003 guidelines, whereas the previous cut-off point for increased risk was $>27 \mathrm{~kg} / \mathrm{m}^{2}$. However, we believe the zone of BMI between 25 and $30 \mathrm{~kg} / \mathrm{m}^{2}$ is heterogeneous in terms of health risk. Many factors beyond BMI influence health risk, such as body fat distribution, physical activity, diet and genetic

\begin{tabular}{ll}
\hline $\begin{array}{l}\text { Table 1: Comparison between } \mathbf{1 9 8 8} \text { and } \\
\text { classification guidelines }\end{array}$ & 2003 guidelines \\
\hline 1988 guidelines & Underweight \\
\hline BMI & $<18.5$ \\
$\begin{array}{l}\text { Zone } A:<20 \\
\text { May be associated with health } \\
\text { problems in some people }\end{array}$ & Normal \\
\hline Zone B: $20-25$ & $18.5-24.9$ \\
Good weight for most people & Overweight \\
\hline Zone C: $25-27$ & $25.0-29.9$ \\
May lead to health problems in & \\
some people & Obese, class I \\
\hline Zone D: $>27$ & $30.0-34.9$ \\
Increased risk of health problems & Obese, class II \\
& $35.0-39.9$ \\
& Obese, class III \\
& $\geq 40.0$ \\
\hline
\end{tabular}

Body-shape indicators of increased risk

Waist:hip ratio cut-off

Waist circumference

Male: 1.0

Male: $\geq 102 \mathrm{~cm}$

Female: 0.8

Female: $\geq 88 \mathrm{~cm}$

Note $: \mathrm{BMI}=$ body mass index $\left(\mathrm{kg} / \mathrm{m}^{2}\right)$. 
background. ${ }^{8}$ For example, some men with high levels of visceral fat display metabolic disturbances that increase their health risk even if their BMI is only marginally elevated. ${ }^{9}$ Other people, such as some premenopausal women, can present low levels of visceral fat and display no deterioration in their metabolic profile even if their BMI approaches $30 \mathrm{~kg} / \mathrm{m}^{2} .^{10}$

The use of waist circumference as proposed in the 2003 guidelines can help to discriminate, among overweight individuals, those who are likely to be at increased risk from those who are not. However, waist circumference values proposed in the 2003 guidelines were given as examples in the $\mathrm{WHO}$ report $^{11}$ and have not yet been validated.

According to the 2003 guidelines, an overweight person with a high waist circumference would display a high health risk, similar to that observed in an obese person with a low waist circumference. The increased health risk associated with a high waist circumference in overweight individuals is well supported by the literature. ${ }^{12}$ However, being overweight and having a low waist circumference is still, according to the 2003 guidelines, an indication of increased risk. In other words, the guidelines suggest that all overweight people are at least at "increased risk" even if their waist circumference is low. The data do not support this assertion: many studies have shown that people who are in the overweight range while showing low levels of abdominal adipose tissue generally display a risk profile similar to that of nonobese subjects. ${ }^{13,14}$ Using a more "severe" criterion to identify overweight people could facilitate the identification of more people who are truly at increased health risk. However, many others will receive an overweight label and will be under increased pressure to lose weight even if their metabolic risk is low. Increased pressure to lose weight can induce body dissatisfaction and lower self-esteem in people who are otherwise in good mental health.

\section{Subcategories in the definition of BMI}

The subclassification of obesity in the new guidelines is helpful, since health risk generally increases, and the level of intervention required varies across BMI categories. ${ }^{15}$ The use of the term "overweight" rather than "pre-obese" (which is used in the WHO guidelines) for BMIs ranging from 25.0 to $29.9 \mathrm{~kg} / \mathrm{m}^{2}$ is also useful, since it describes actual weight status rather than a status that may precede obesity. Because some people with a BMI between 25.0 and $29.9 \mathrm{~kg} / \mathrm{m}^{2}$ will never become obese, this BMI range should not be systematically considered to indicate a pre-obese state. Finally, in the 2003 guidelines, weight terms rather than health terms are used to describe the different BMI categories. Once again, we feel comfortable with this change, since the use of weight terms reflects a direct appreciation of an actually measured variable, BMI, rather than a more indirect inference of the health status associated with BMI.

\section{Conclusion}

Updating the guidelines on body weight for Canadians was well justified in light of the considerable advances in the field of body weight and related metabolic disorders since 1988. The authors of the Canadian Guidelines for Body Weight Classification in Adults indicate that the guidelines are intended for health professionals, researchers and educators involved in research and practice related to body weight. However, it may be difficult for a single tool to meet all these needs. Indeed, a number of important clinical factors are absent from the report: special considerations for elderly people, ethnic differences, physical activity and diet. For example, although dietary habits are identified as a way to counterbalance the health hazard associated with obesity, the assessment and definition of "desirable" dietary habits are not provided in the document. The absence of concrete answers to relevant clinical scenarios weakens the practical application of the guidelines. It can be easily predicted that some health professionals will apply the new guidelines without taking all the limitations and exceptions into consideration. Although the 2003 guidelines are useful, they should be applied with caution. Continuing education will be important in assisting health professionals in their interpretation and use.

From the Département des sciences des aliments et de nutrition, Université Laval (Lemieux), Institut national de santé publique du Québec (Mongeau), Département de kinésiologie, Université de Montréal (Laberge), Ministère de la santé et des services sociaux du Québec (Lachance).

Competing interests: None declared.

Contributors: All the authors contributed substantially to the conception and design of this article. Simone Lemieux drafted the article. Lyne Mongeau, MarieClaude Paquette, Suzanne Laberge and Brigitte Lachance made substantive revisions. All authors approved the final version submitted for publication.

\section{References}

1. Office of Nutrition Policy and Promotion. Canadian guidelines for body weight classification in adults. Ottawa: Health Canada; 2003. Available: www.hc-sc.gc.ca /hpfb-dgpsa/onpp-bppn/cg_bwc_introduction_e.html (accessed 2004 Oct 26).

2. Health and Welfare Canada. Canadian guidelines for healtby weights. Report of an expert group convened by Health Promotion Directorate, Health Services and Promotion Branch. Ottawa: Health and Welfare Canada; 1988.

3. World Health Organization. Obesity: preventing and managing the global epidemic. Report of a WHO Consultation on Obesity. Geneva: The Organization; 2000.

4. Singh PN, Lindsted KD. Body mass and 26-year risk of mortality from specific diseases among women who never smoked. Epidemiology 1998;9:246-54.

5. Rexrode KM, Hennekens CH, Willett WC, Colditz GA, Stampfer MJ, RichEdwards JW, et al. A prospective study of body mass index, weight change, and risk of stroke in women. $7 A M A$ 1997;277:1539-45.

6. Katzmarzyk PT, Craig CL, Bouchard C. Underweight, overweight and obesity: relationships with mortality in the 13-year follow-up of the Canada Fitness Survey. 7 Clin Epidemiol 2001;54:916-20.

7. Ledoux M, Mongeau L, Rivard M. Poids et image corporelle. In: Institut de la statistique du Québec, editor. Enquête sociale et de santé auprès des enfants et des adolescents québécois 1999. Québec: Les Publications du Québec; 2002. p. 311-44.

8. Kissebah AH, Krakower GR. Regional adiposity and morbidity. Physiol Rev 1994;74:761-811.

9. Yamamoto M, Egusa G, Hara H, Yamakido M. Association of intraabdominal fat and carotid atherosclerosis in non-obese middle-aged men with normal glucose tolerance. Int 7 Obes Relat Metab Disord 1997;21:948-51.

10. Després JP, Nadeau A, Tremblay A, Ferland M, Moorjani S, Lupien PJ, et al. Role of deep abdominal fat in the association between regional adipose tissue distribution and glucose tolerance in obese women. Diabetes 1989;38:304-9.

11. World Health Organization. Obesity: preventing and managing the global epidemic. Report on a WHO consultation on obesity. Geneva: The Organization; 1997. 
12. Zhu S, Wang Z, Heshka S, Heo M, Faith MS, Heymsfield SB. Waist circumference and obesity-associated risk factors among whites in the third National Health and Nutrition Examination Survey: clinical action thresholds. Am 7 Clin Nutr 2002;76:743-9.

13. Ohlson LO, Larsson B, Svardsudd K, Welin L, Eriksson H, Wilhelmsen L, et al. The influence of body fat distribution on the incidence of diabetes mellitus: 13.5 years of follow-up of the participants in the study of men born in 1913. Diabetes 1985;34:1055-8.

14. Lemieux I, Pascot A, Couillard C, Lamarche B, Tchernof A, Almeras N, et al. Hypertriglyceridemic waist: a marker of the atherogenic metabolic triad (hyperinsulinemia; hyperapolipoprotein B; small, dense LDL) in men? Circu- lation 2000;102:179-84

15. National Institutes of Health. The practical guide: identification, evaluation and treatment of overweight and obesity in adults. Bethesda (MD): The Institutes; 2000.

Correspondence to: Dr. Simone Lemieux, 2440 Hochelaga Blvd., Institute of Nutraceuticals and Functional Foods, Laval University, Québec QC G1K 7P4; fax 418 656-5877;

simone.lemieux@aln.ulaval.ca

\section{Transparency in drug regulation: Mirage or oasis?}

\section{Joel Lexchin, Barbara Mintzes}

I n Canada, the information used to approve new drugs is deemed commercially sensitive and hence confidential under the Access to Information Act, ${ }^{1}$ and the Therapeutic Products Directorate (TPD) will not release such information without the manufacturer's approval. As a consequence, safety and efficacy information contained in unpublished trials submitted to the TPD is generally unavailable to researchers, physicians and patients, a situation that can potentially lead to the inappropriate prescribing and use of medications.

The standard argument for the legal protection of these data is that their disclosure would compromise the economic interests of drug manufacturers. This rationale is difficult to credit in view of experience in other jurisdictions. The US Food and Drug Administration (FDA) discloses research information from preclinical and clinical trials that is considered proprietary in Canada, without apparent negative effects on companies' profitability or willingness to operate in the US market. For example, extensive information on rosuvastatin is available on the FDA's Web site. ${ }^{2}$

On the other hand, nondisclosure has serious disadvantages for the TPD, health professionals and the Canadian public. If scientific data submitted to regulatory agencies are never disclosed or allowed to enter normal peer-review channels, neither these data nor TPD reviewers' evaluations can become subject to scrutiny by independent scientists. The scientific atmosphere of the agency may be stifled and the professional growth of its staff severely inhibited. ${ }^{3}$ Deprived of any independent access to information, health professionals and the public must accept the TPD's judgement about the safety and effectiveness of products.

The level of secrecy in the TPD has been criticized on a number of occasions, including in a 2000 report by the ad hoc Committee on the Drug Review Process of Health Canada's own Science Advisory Board. The report stated:
$[\mathrm{I}] \mathrm{n}$ our view and that of many stakeholders, the current drug review process is unnecessarily opaque. Health Canada persists in maintaining a level of confidentiality that is inconsistent with public expectation and contributes to a public cynicism about the integrity of the process. ${ }^{4}$

To remedy this situation the Committee recommended

that HPB [Health Protection Branch, now Health Products and Food Branch] should set new standards of access to information at all stages of the drug review process, enhancing transparency and public confidence. ${ }^{4}$

In 2004 a report by the House of Commons Standing Committee on Health supported the development of mechanisms to enable greater public disclosure of information about clinical trials. ${ }^{5}$

In response to these calls for greater transparency, the TPD announced in 2004 that when new drugs and devices are approved it would publish a document entitled the Summary Basis of Decision (SBD). The SBD would outline the scientific and benefit/risk-based reasons for the TPD's decision to grant market authorization for a product. ${ }^{6}$

The key part of the SBD of importance to prescribers and consumers is the clinical information on drug effectiveness and safety. Is enough information provided to allow for the safe and rational use of new medications or extension of indications for previously approved drugs?

To evaluate the adequacy of information in the SBDs, we examine 3 recent cases in which unpublished data submitted to drug regulators contained important clinical information that was either unavailable or misrepresented within the published literature. We ask whether the same discoveries would have been possible using Health Canada's SBDs. We based our assessment on 2 pilot SBDs published to date, one for rosuvastatin, ${ }^{7}$ a cholesterol-lowering medication, the second for agalsidase beta, ${ }^{8}$ an enzyme replacement for use in Fabry's disease. 